\title{
First tests of using an electronic nose to control biogas plant efficiency
}

\author{
Federica Borgonovo, Annamaria Costa, Massimo Lazzari \\ Department of Health, Animal Science and Food Safety (VESPA), Faculty of Veterinary Medicine, \\ Università degli Studi di Milano, Milan, Italy
}

\begin{abstract}
The demand for online monitoring and control of biogas process is increasing, since better monitoring and control system can improve process plants stability and economy. A number of parameters,such as gas production, $\mathrm{pH}$, alkalinity, Volatile Fatty Acids (VFA) and $\mathrm{H}_{2}$, in both the liquid and the gas phase have been suggested as process indicators. For different reasons these indicators do not offer enough information to build a consistent feedback control able to promptly forecast and solve plants working problems. The study proposes the use of unconventional complex sensors as a possible solution to engineer a reliable control system. Tests to analyze the biogas coming from a plant were performed using an electronic nose (Airsense PEN 2, AIRSENSE Analytics $\mathrm{GmbH}$ ). In particular, a 108 olfactometric fingerprinting reference database obtained by different combination of VFA (acetic, propionic e butyric acids, pure or in solution with water) was initially determined. As a second step, the e-nose was tested to verify a potential difference in the analysis of gases emitted by digested manure. Statistic multivariate analysis confirm that the e-nose can distinguish the manure and digester mixed liquor aromatic emission proving the possibility of using this technology as possible base for a biogas control system.
\end{abstract}

\section{Introduction}

The increasing awareness in renewable energy and green energy improved the development of biogas technology, especially farm biogas plants (Holm et al., 2009).

Anaerobic digestion (methane fermentation) is a biotechnological process utilizing biomasses, mainly waste, to produce valuablebiogas.

Correspondence: Massimo Lazzari, Department of Health, Animal Science and Food Safety (VESPA), Faculty of Veterinary Medicine, Università degli Studi di Milano, via Celoria 10, 20133 Milan, Italy.

Tel. +39.02 .50318047 - Fax: +39.02 .50317909 .

E-mail:massimo.lazzari@unimi.it

Key words: biogas plant, anaerobic digestion, process overloading, e-nose.

Contributions: the authors contributed equally.

(C) Copyright F. Borgonovo et al., 2013

Licensee PAGEPress, Italy

Journal of Agricultural Engineering 2013; XLIV(s2):e109

doi:10.4081/jae.2013.s2.e109

This article is distributed under the terms of the Creative Commons Attribution Noncommercial License (by-nc 3.0) which permits any noncommercial use, distribution, and reproduction in any medium, provided the original author(s) and source are credited.
Biogas can be produced by mesophilic and termophilic plants. During the methanogenesis process, manure, that can be added with biomasses to adjust the anaerobic digestion, is converted to mono and oligomers (aminoacids, long chain fatty acids, saccharides). The substrate fermentation leads mainly to volatile fatty acids (VFA) and acetic acid followed by gases $\left(\mathrm{H}_{2}, \mathrm{CO}_{2}\right)$ which,in the last step, are transformed to methane and $\mathrm{CO}_{2}$. In the meanwhile, the concentration of simple ions and $\mathrm{pH}$ varies.

According to environmental fluctuations and for changes in plant feeding, the anaerobic digestion can be altered by many factors(Ward $e t$ al., 2008). For this reason a continuous digestion and plant monitoring is needed to avoid the system instability. A wide number of indicators as volatile fatty acids evaluation (VFAs), $\mathrm{pH}$, redox potential, biogas production rate, and composition - to monitor the correct anaerobic digestion are used. Among these indicators, VFA and biogas production are widely considered as the two most crucial and direct indicators of the system status (Holm et al., 2008), since the increase in VFA concentration is linked tothe methanogenesis inhibition or organic overloading, and implies a risk of process upset (Hansson et al., 2003).

VFAs detection can be performed through fluorescence spectroscopy (Madsen et al., 2011; Pearce et al., 2003), near-infrared (NIR) spectroscopy (Nicolas et al., 2001), titration (Cimander et al., 2002) and gas chromatography(Liden et al., 1998).

Other techniques, extremely useful to detect the quality of the fermentation process status, are the biogas composition and the production rate (Holm et a, 2007; Holm et al., 2008).

Because of the high complexity of biogas plants and fermentation status the interrelations of the many involved parameters remain unclear. In this frame, a wide adopted technique is to set a threshold values for some individual indicators like $\mathrm{pH}$ and VFA. These last ones are considered as the most relevant state variables for process monitoring, and are used to judge thereactor status on the basis of the detected values. However, once the threshold values are reached can only reveal the current reactor status, but it is actually, in most cases, too late for an effective process control.

A promising alternative approach is to use the electronic nose.

The electronic nose is a biologically inspired system composed of an array of non-specific gas sensors (Pearce et al., 2003). When sensor responses are put together, they form a pattern, which is typical of the gas mixture. In this way, the sensors responses produce characteristic patterns for each chemical mixture exposed to the sensor array. By presenting many different chemicals to the sensor array, a patterns database is built up and used to train the pattern recognition system that finally allows recognizing a gas mixture. More extensive information about e-nose technology can be found in Pearce et al., 2003.

The first e-nose technology use was applied to the monitoring of the anaerobic digestion process by Nordberg et al. 2000. More recently, the electronic nose was proposed as an innovative online monitoring to autoalert and control the system (Adam et al., 2013).

The main aim of this work was to determine the correct technique to use an e-nose as a discriminator in anaerobic digestion status.

Indirectly, this study is leaded to investigate the e-nose technology as a new robust, simple, sensitive tool for biogas production monitor- 
ing in order to optimize the process and increase gas yield in small scale agricultural plants.

\section{Materials and methods}

In the present study, a preliminary test on the e-nose ("Airsense PEN 2", AIRSENSE Analytics $\mathrm{GmbH}$ ) abilityto detect the biogas plant overloading was performed, analyzing both gases and manure samples collected in vials.To this purpose:

1. As a first step, the olfactometric fingerprints of VFAs (acetic, propionic and butirric acids) in purity or diluted with deionized water (around 108 combinations) were determined, in order to represent the VFAs produced during the anaerobic digestion process. The "training set" obtained in laboratory conditions represented the olfactometric fingerprints reference database of the biogas contained in the headspace of the minireactors.

2. As a second step, the e-nose was tested to verify a potential difference in theanalysis of gases emitted by digested manure (collected in nalophan bags) and by manure itself, in order to set up the proper experimental conditions.

\section{Odor analysis}

Manure samples odor were analyzed by means of a PEN 2 electronic nose (WMA Airsense, Schwerin, Germany). It consists of: a sampling unit; a sensor array made up of ten metal oxide semiconductor (MOS, see Table 1) chemical sensors; a software for data storage and multivariate statistical processing (pattern recognition system). During sampling, two hypodermic needles were inserted through the vial rubber cap into the headspace. The first needle was connected to the sampling unit, while the second was connected to a charcoal filter by means of a polytetrafluoroethylene (PTFE, Teflon) hose. Odor analysis was performed in a two step way: measurement and standby. Electro-valves, controlled by a computer program, guided the air through different circuits depending on the stage of the analysis. Irrespective of the phase, airflow in the measurement chamber was kept constant (Table 2). During the measurement phase, the sampling unit "inhaled" the volatile gases present in the vial headspace and sent them - at a constant rate $\left(6.67 \mathrm{~mL} \mathrm{~s}^{-1}\right)$ - to the measurement chamber causing changes in sensor's conductance: this phase lasted $80 \mathrm{~s}$, which was enough time for the sensor signals to reach a stable value. When a measurement was completed, a standby phase of $160 \mathrm{~s}$ was activated.

Table 1. Sensors of the PEN 2 electronic nose (WMA Airsense, Schwerin, Germany).

\begin{tabular}{|c|c|c|c|}
\hline Number in array & Sensor-name & General description & Reference \\
\hline 1 & Wic & Aromatic compounds & Toluene, $10 \mathrm{ppm}$ \\
\hline 2 & w5s & $\begin{array}{l}\text { Very sensitive, broad range sensitivity, react on nitrogen oxides, } \\
\text { very sensitive with negative signal }\end{array}$ & $\mathrm{NO}_{2}, 1 \mathrm{ppm}$ \\
\hline 3 & w3C & Ammonia, used as sensor for aromatic compounds & Benzene, 10ppm \\
\hline 4 & W6S & Mainly hydrogen, selectively (breath gases) & $\mathrm{H}_{2}, 100 \mathrm{ppb}$ \\
\hline 5 & w5C & Alkanes, aromatic compounds, less polar compounds & Propane, 1 ppm \\
\hline 6 & Wis & $\begin{array}{l}\text { Sensitive to methane (environment) ca. } 10 \mathrm{ppm} \text {. Broad range, } \\
\text { similar to No. } 8\end{array}$ & $\mathrm{CH}_{3}, 100 \mathrm{ppm}$ \\
\hline 7 & WIW & $\begin{array}{l}\text { Reacts on sulphur compounds, } \mathrm{H}_{2} \mathrm{~S} 0.1 \mathrm{ppm} \text {. Otherwise } \\
\text { sensitive to many terpenes and sulphur organic compounds, } \\
\text { which are important for smell, limonene, pyrazine }\end{array}$ & $\mathrm{H}_{2} \mathrm{~S}, 1 \mathrm{ppm}$ \\
\hline 8 & W2S & Detects alcohols, partially aromatic compounds, broad range & $\mathrm{CO}, 100 \mathrm{ppm}$ \\
\hline 9 & W2W & Aromatics compounds, sulphur organic compounds & $\mathrm{H}_{2} \mathrm{~S}, 1 \mathrm{ppm}$ \\
\hline 10 & w3S & $\begin{array}{l}\text { Reacts on high concentrations }>100 \mathrm{ppm} \text {, sometime very } \\
\text { selective (methane) }\end{array}$ & $\mathrm{CH}_{3}, 10 \mathrm{CH}_{3}, 100 \mathrm{ppm}$ \\
\hline
\end{tabular}

Table 2. Summary of the operating conditions of the e-nose during headspace analysis of manureodor).

\begin{tabular}{lc} 
Operating condition & \\
Transport gas & Ambient air (cleaned by charcoal filter) \\
Sampling rate & $10 \mathrm{~mL} \mathrm{~s}^{-1}$ \\
\hline Amount of sample/vial & $6.67 \mathrm{~mL} \mathrm{~s}^{-1}$ \\
Vial volume & $20 \mathrm{~mL}$ \\
\hline Data acquisition & $1800 \mathrm{~s}$ \\
Headspace generation time & $80 \mathrm{~s}$ \\
Sampling time & $160 \mathrm{~s}$ \\
\hline Flushing time & $240 \mathrm{~s}$ \\
\hline Total measurement time
\end{tabular}


Its purpose was to clean the circuit, and the measurement chamber in particular, in order to return the sensor signals to their baselines. During this phase, clean air entered the circuit, crossing the measurement chamber first and pushing the remaining volatiles out of the circuit itself.

The ten MOS chemical sensors comprising the sensor array operated by transduction of the chemical compounds in the manure aroma into electric signals (Yuwono and Lammers, 2004). At the end of the measurement, these signals were recorded and stored, to be analyzed either by the software of the pattern recognition system or by statistical analysis software. One pattern comprises the signals from all ten sensors taken during the measurement of a sample.

The software records the variations occurring in the ratio $(\mathrm{G} / \mathrm{G} 0)$ between the conductance of each sensor, $G(\Omega-1)$, at each second of measurement and the reference, $\mathrm{G} 0(\Omega-1)$, which is the conductance that the sensor shows when clean charcoal-filtered air enters the measurement chamber.

\section{PCA and discriminant analysis}

To increase the knowledge attained from the considered variables and, according to them, try to discriminate as much as differences as possible during the manure monitoring, data were submitted to principal component analysis (PCA) followed by discriminant analysis. PCA is a linear, unsupervised pattern-recognition technique very useful for analyzing, classifying, and reducing the numerical datasets dimensionality in multivariate problems (Todeschini, 1998).

Linear Discriminant Analysis (LDA) (Meloun et al., 1992) is one of the mostly used classification procedure which maximizes the variance between categories and minimizes the variance within categories. The dataset was preparedusing the signals recorded during the measurement last $5 \mathrm{~s}$ when sensor signals were stable meaning that an equilibrium between their sensitivity and the sample manurevolatile compounds was achieved. Statistical analysiswascarried out using Scan for Windows.

\section{Results}

Building of an olfactometric "training set" based on odor emitted by mixed compounds of acetic, propionic and butirric acid. The choice to analyse VFA was linked to their capacity to be used as good indicators of digestion process: in particular,as shown in the Figure 1, during overloading or stress episodes corresponding to the rise of the partial hydrogen pressure, propionic acid is more instable than acetate and buthirrate (Boe, 2006).

Results of PCA analysis related to the analysis of gases emitted by digested manure (collected in nalophan bags) and by manure itself are reported in the following Figure 2. Items called with numbers are referred to manure samples (G1...G8) and indicates the air sampled in the minireactors headspace.This preliminary trial was conducted to test the e-nose potential performances differences to detect samples as gases emitted by manure during digestion or as manure itself.

The score plot reported in Figure 2 showed that both procedures gave good results, since either gases samples or manure samples resulted suitable in the two identification groups by the e-nose (G1, G4, G5 and G8 were symmetrically in the graphic opposed to $1,4,5$ and 8 with respect to the second component; G2, G3, G6 andG7 were opposed to 2 , 3,6 and 7 with respect to the first component.

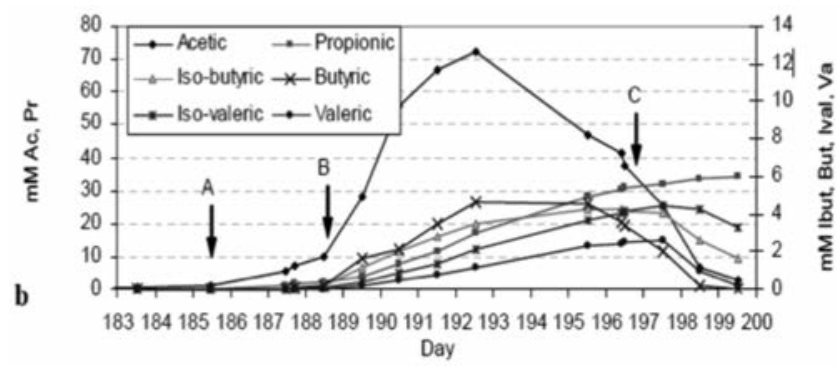

Figure 1. VFA concentration during an organic overloading (in normal conditions before " $A$ ", from " $A$ " on adding fiber and rapeseed oil, from point " $B$ " start adding glucose, from point " $C$ " back to normal feed again (from Boe, 2006, On line monitoring and control of the biogas process).

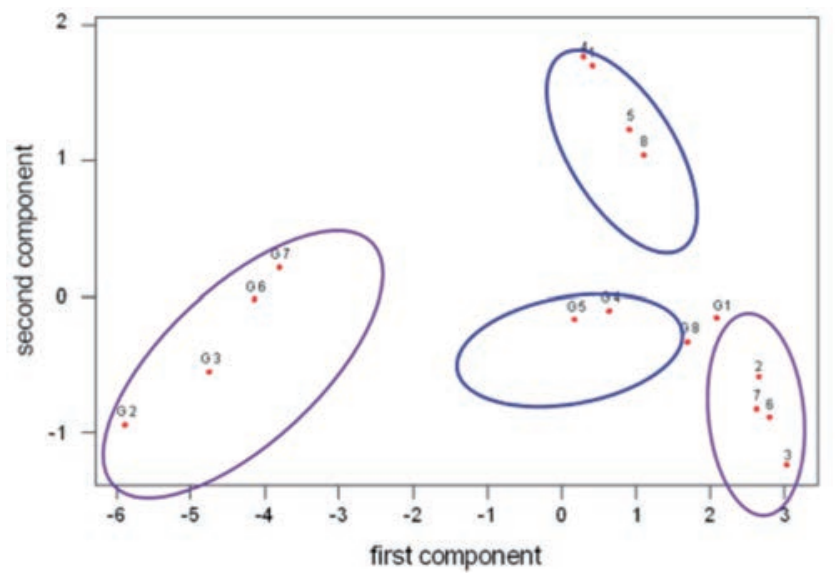

Figure 2. Score plot provided by PCA analysis. Items called with numbers are referred to manure samples (G1...G8) and indicates the air sampled in the minireactors headspace.

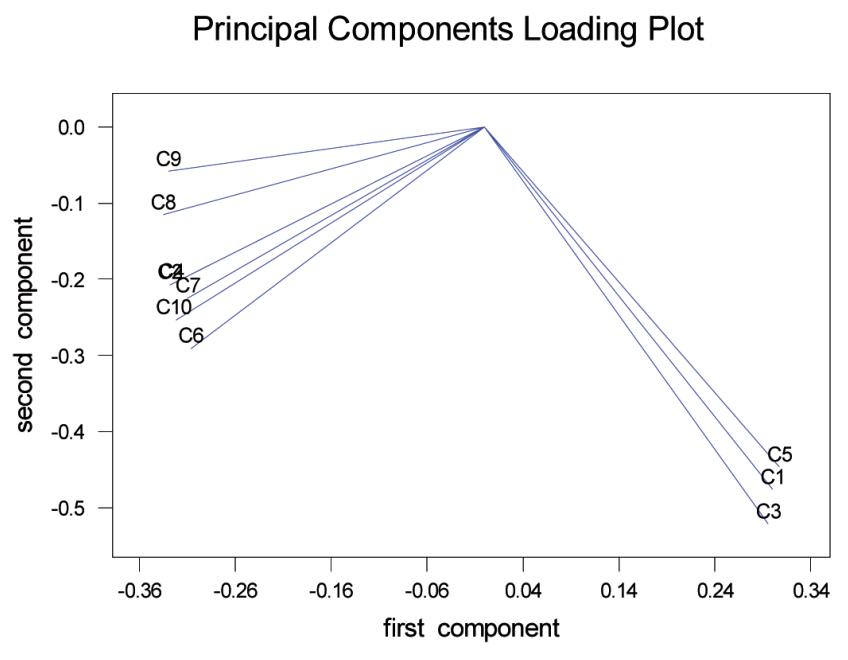

Figure 3. Loading plot provided by PCA analysis. 


\section{Conclusions}

Electronic nose demonstrated its potential to detect gases emitted by manure during digestion or as manure itself. This procedure can represent a correct technique to monitor, in further studies, the biomethanation process and to discriminate overload situations of anaerobic plants.

\section{References}

Boe K, Batstone DJ, Angelidaki I (2007) An innovative online VFA monitoring system for the anaerobic process, based on headspace gas chromatography. BiotechnolBioeng 96(4):712- 721. doi:10.1002/ bit.21131

Boe K, Batstone DJ, Steyer J-P, Angelidaki I (2010) State indicators for monitoring the anaerobic digestion process. Water Res 44(20):5973-5980. doi:10.1016/j.watres.2010.07.043

Cimander C, Bachinger T, Mandenius C-F (2002) Assessment of the performance of a fed-batch cultivation from the preculture quality using an electronic nose. BiotechnolProg 18(2):380-386. doi: 10.1021/bp010166j

Cimander C, Carlsson M, Mandenius C-F (2002) Sensor fusion for online monitoring of yoghurt fermentation. J Biotechnol 99(3):237248. doi:10.1016/s0168-1656(02)00213-4

Gilles Adam, SebastienLemaigre, Anne-Claude Romain, Jacques Nicolas, Philippe Delfosse. 2013. Evaluation of an electronic nose for the early detection of organic overload of anaerobic digesters. BioprocessBiosystEng 36:23-33. DOI 10.1007/s00449-012-0757-6

Hansson M, Nordberg $\mathrm{A}^{\circ}$, Mathisen B (2003) On-line NIR monitoring during anaerobic treatment of municipal solid waste. Water Sci Technol 48(4):9-13

Holm-Nielsen JB (2008) Process analytical technologies for anaerobic digestion systems. PhDThesis, Aalborg University, Esbjerg. ISBN 978-87-7606-030-5

Holm-Nielsen JB, Al Seadi T, Oleskowicz-Popiel P (2009) The future of anaerobic digestion and biogas utilization. Bioresour Technol100(22):5478-5484. doi:10.1016/j.biortech.2008.12.046

Holm-Nielsen JB, Andre e H, Lindorfer H, Esbensen KH (2007) Transflexive embedded near infrared monitoring for key process intermediates in anaerobic digestion/biogas production. J NearInfraredSpectrosc 15(2):123-135. doi:10.1255/jnirs.719

Holm-Nielsen JB, Lomborg CJ, Oleskowicz-Popiel P, Esbensen KH (2008) On-line near infrared monitoring of glycerol-boosted anaerobic digestion processes: evaluation of process analytical technologies. BiotechnolBioeng 99(2):302-313. doi:10.1002/bit.21571

Lide n H, Mandenius C-F, Gorton L, Meinander NQ, Lundstro“m I, Winquist F (1998) On-line monitoring of a cultivation using an electronic nose. AnalChim Acta 361(3):223-231. doi:10.1016/

Madsen M, Holm-Nielsen JB, Esbensen KH (2011) Monitoring of anaerobic digestion processes: a review perspective. RenewSustain Energy Rev 15(6):3141-3155. doi:10.1016/j.rser.2011.04.026

Nicolas J, Romain A-C, Andre P (2001) Chemometrics methods for the identification and the monitoring of an odour in the environment with an electronic nose. In: Sensors and chemometrics. Research Signpost, India, pp 75-90

Nordberg A, Hansson M, Sundh I, Nordkvist E, Carlsson H, Mathisen B (2000) Monitoring of a biogas process using electronic gas sensors and near-infrared spectroscopy (NIR). Water Sci Technol 41(3):1-8

Pearce TC, Schiffman SS, Nagle HT, Gardner JW (2003) Handbook of machine olfaction: electronic nose technology. ISBN: 978-3-52760563-7

Pearce TC, Schiffman SS, Nagle HT, Gardner JW (2003) Handbook of machine olfaction: electronic nose technology. ISBN: 978-3-52760563-7

s0003-2670(98)00035-x

Ward AJ, Hobbs PJ, Holliman PJ, Jones DL (2008) Optimisation of the anaerobic digestion of agricultural resources. Bioresource Technology 99(17):7928-7940.

Yuwono, A. S., and P. S. Lammers. 2004. Odor polluting in the environment and the detection instrumentation. Agric. Eng. Intl., vol. VI: Invited overview paper. 